\title{
Analysis of Wheel Squeal and Flanging on Curved Railway Tracks
}

\author{
Jae Chul Kim ${ }^{1}$ - Yang Soo Yun ${ }^{2} \cdot$ Hee-Min $\mathrm{Noh}^{1}$ (1)
}

Received: 6 March 2019 / Revised: 1 September 2019 / Accepted: 2 September 2019 / Published online: 26 September 2019 (c) The Author(s) 2019

\begin{abstract}
When a railway vehicle moves over a sharply curved section of track, intense high-frequency noises sometimes occur. These are potentially a source of annoyance to those living adjacent to railway tracks. To efficiently identify measures appropriate to reduce curve squeal, it is important to determine the dominant noise type. However, it is difficult to analyze the various noises made over curved sections of railway using general noise measurements. In this study, we analyzed squealing and flange noises using various experimental approaches. We first investigated the noise characteristics of the railway vehicle via structural analysis of the wheel. It was confirmed that a wheel has various natural frequencies and eigenmodes in the high frequency range, i.e. over $1000 \mathrm{~Hz}$. A roller rig test was performed to measure and investigate the characteristics of the noise generated when an actual wheel and the curved section of the railway track come in contact with each other. In this experiment the squeal and the flange noises, in particular, were reproduced by adjustments made to the lateral angle and vertical force, respectively. Results confirmed that the squealing noise occurs in the high frequency region and the flange noise occurs in various modes. A study was also conducted to measure and analyze the noise in the actual curved section of an urban railway. By comparing the frequency analysis and the natural frequency analysis of the noise that was actually measured, the mode by which the wheel caused the squealing noise was confirmed. Furthermore, the influence of the noise generated inside and outside the curved section of the track was investigated based on velocity, and the influence of the former on the noise generated was also examined. This study provides information on the squeal and flange noises generated when a railway vehicle moves over a curved section of a railway using various experimental approaches.
\end{abstract}

Keywords Curve squeal $\cdot$ Experimental analysis $\cdot$ Flange noise $\cdot$ Lateral creep force $\cdot$ Railway noise

\section{Introduction}

High-pitched noises, typically squeals and flange noises, are generated on the curved portion of a railway track, which elicits complaints from train passengers and those who live near sections of curved track $[1,2]$. They are not easy to reduce because they are generated even when a train travels at a low speed. Therefore, research has been carried out to analyze squealing and flange noises through various measurements.

Hee-Min Noh

hmnoh@krri.re.kr

1 Transportation Environmental Research Team, Korea Railroad Research Institute, 176, Cheldobangmulgwan-ro, Uiwang-si, Gyeonggi-so 234-567, South Korea

2 Railway System Engineering, University of Science and Technology, 217, Gajeong-ro, Yuseong-gu, Daejeon 305-350, South Korea
In the mid-1970s, Rudd [3] reported that the cause of noise at curved portions of rail was the lateral creep caused by contact between the wheel and rail, contact between the side of the rail head and the wheel flange, and the slip differential between the left and right wheels. Current definitions classify curve squeal as wheel noise resulting from lateral creep and flange noise as that due to contact between the wheel flange and rail gauge [4]. Generally, squeal noise of $100-110 \mathrm{~dB}$ is generated when a train passes through a curve about $7.5 \mathrm{~m}$ from the center of the rail; this is $15-20 \mathrm{~dB}$ higher than the rolling noise of the vehicle, and one or more pure tone noises occur at frequencies of $400-10,000 \mathrm{~Hz}$ [5]. Curve noise is generated mainly in sections of a track with a curve radius of less than $300 \mathrm{~m}$. If the ratio of the axle distance to the curve radius is 100 or less, the probability of generating a squealing noise is high $[6,7]$. Flange noise manifest differently based on the contact position of the wheel and the rail when the curve is passed over [8]. 
Wheel squeal and flange noises are generated at the front inner wheel and the outer wheel of the bogie, respectively.

Friction modifiers are widely used to reduce the noise generated in curved portions of track. However, it is not easy to establish precise mitigation measures without analyzing the characteristics of squeal and flange noises. This study derived the characteristics of the squeal and flange noises over curved sections of track. We investigated the noise characteristics of trains via structural analysis of the wheel. It was confirmed that the wheel has various natural frequencies and eigenmodes in the high frequency range. A roller rig test was performed to measure and investigate the characteristics of the noise generated when an actual wheel and the curved section of the railway track come in contact with each other. In this experiment the squeal and the flange noises, in particular, were reproduced by adjustments made to the lateral angle and vertical force, respectively. Results confirmed that the squealing noise occurs in the high frequency region and the flange noise occurs in many modes. A study was also conducted to measure and analyze the noise in the actual curved section of an urban railway. By comparing the frequency analysis and the natural frequency analysis of the noise that was actually measured, the mode by which the wheel caused the squealing noise was confirmed. Furthermore, the influence of the noise generated inside and outside the curved section of the track on was investigated based on velocity, and the influence of the former on the noise generated was also examined. This study provides information on the squeal and flange noises generated when a railway vehicle moves over a curved section of a railway using various experimental approaches.

\section{Theoretical Background on Squeal and Flange Noise}

If the axle of the vehicle moves in a transverse manner when passing over a curve, a transverse slip occurs between the wheel and the rail. The difference between the actual transverse speed of the wheel and the pure transverse speed is referred to as lateral creep. The transverse tangential force generated between the wheel face and the railhead, when the axle moves laterally, is called the lateral creep force. The relationship between the lateral creep ratio and friction coefficient based on contact between a train and the railway track is shown in Fig. 1. The characteristics of this friction change based on the material and geometry of the wheel and the rail, and the material between the wheel and contact surface. The friction coefficient gradually increases with creep rate; when the former reaches its maximum value, it decreases as the creep rate increases. When the gradient of the friction coefficient against the increase in the creep rate becomes negative, the damping coefficient becomes negative at the

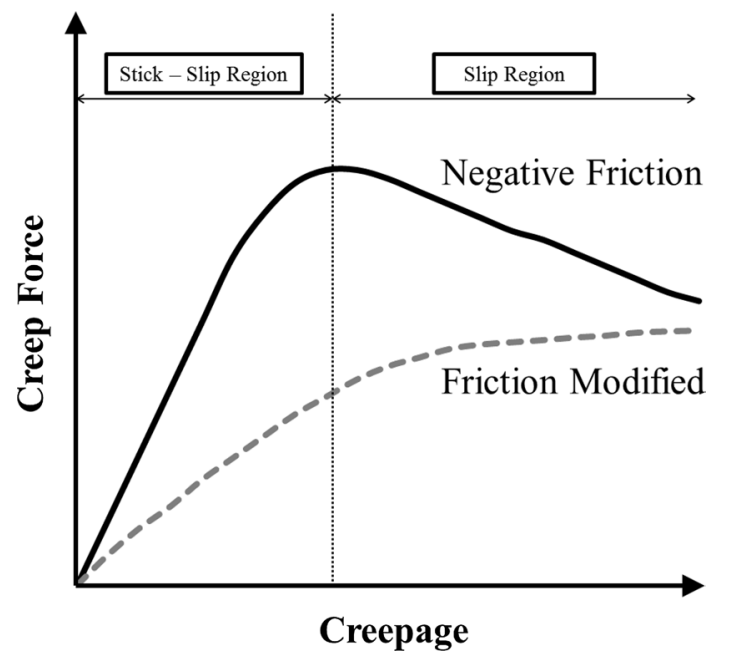

Fig. 1 Characteristics of creep force

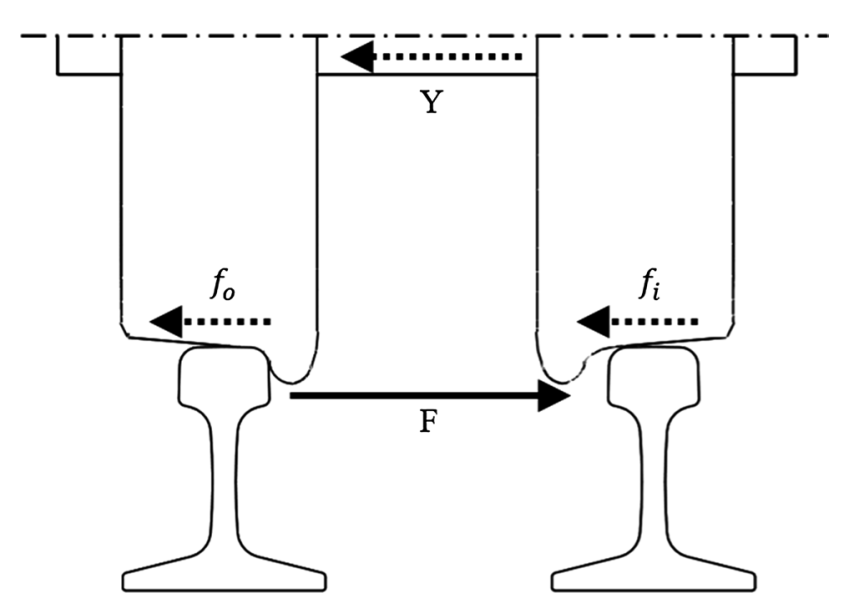

Fig. 2 Forces between wheel flange and face of the rail gauge

specific natural vibration frequency of the wheel, which generates a self-excited vibration. Therefore, if the damping coefficient of the wheel increases, or if the gradient of the friction coefficient with respect to the creep ratio is nonnegative, the curve squeal can be reduced. Sound-insulating wheels and friction-adjusting materials have been developed to address this cause of noise.

Noise and abrasion due to wheel and rail head contact between the wheel and railhead occurs on the outer rail when the wheel passing passes over through a curve. Flange noise from the wheel depends on the its flange force of the wheel acting on the side of the rail head. Moreover, reducing the flange force not only prevents flange noise, but also is very effective in preventing wear on the wheel flange and the side of the rail side head. Flange contact force $F$ is shown illustrated in Fig. 2; in which the lateral pressure $Y$, caused by the vehicle's excessive centrifugal force of the vehicle; 
the lateral creep force $f_{i}$ of the inner rail; and lateral creep force $f_{0}$ of the outer rail are expressed as follows:

$F=Y+f_{i}+f_{0}$

The lateral pressure is determined by driving conditions and the structure of the vehicle, and the lateral creep force of the inner and outer rails is determined by the creep ratio and friction characteristics. Therefore, when a friction-adjusting material is used, the lateral creep force is reduced relative to the creep ratio. The flange force is also reduced, thereby decreasing flange noise and wear.

\section{Modal Analysis of the Wheel}

The natural frequencies (particularly the main frequency characteristics) and eigenmodes of the wheel, which is the main source of squeal and flange noise, was analyzed using experimental and analytical methods. Since the curve noise occurs at the natural frequency of the wheel, we measured its frequency response function with an impact hammer as shown in Fig. 3. The sensor used in the impact hammer experiment was a PCB 3-axis accelerometer, a B\&K 8200 impact hammer was used for the excitation, and a SIEMENS SCADAS Mobile was used for the measurement. The wheel shaft used in this measurement, which was $860 \mathrm{~mm}$ in diameter, was made of wrought steel. The distance between its faces was $1494 \mathrm{~mm}$ and it weighed $1340 \mathrm{~kg}$ in total. The wheel-set was suspended by a crane, so that the thread and flange of the wheel were not in contact with the rail. The impact hammer was used

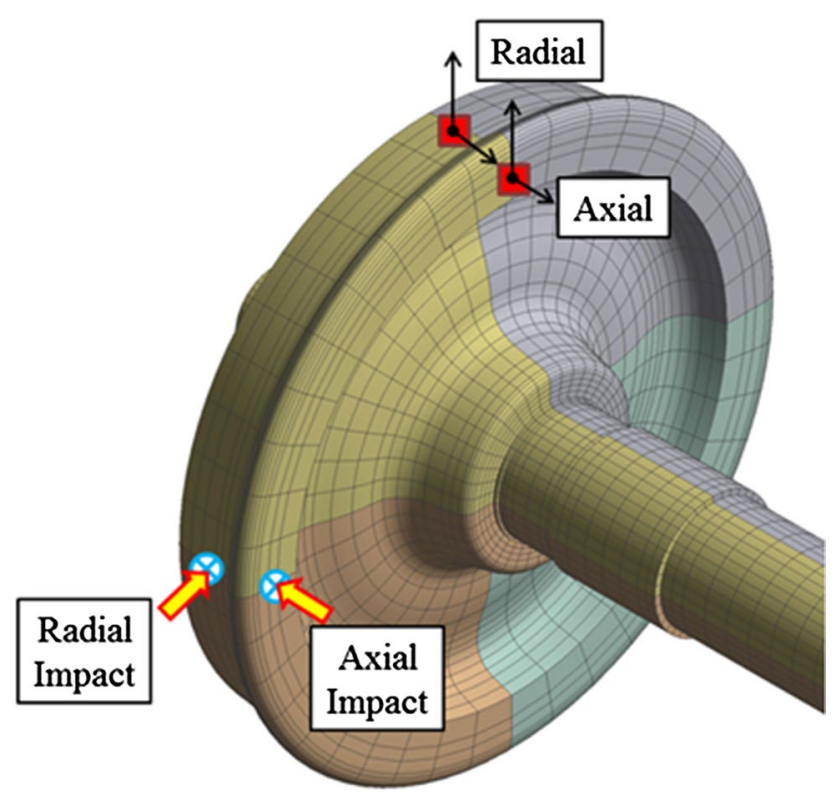

Fig. 3 Positions of impact and response for wheel to excite the thread and flange of the wheel vertically, and the response characteristic was confirmed. Acceleration sensors capable of measuring in three directions were attached to the thread and flange of the wheel to measure the response characteristics in the axial direction and the radial direction simultaneously. Sampling frequency was set to $20,480 \mathrm{~Hz}$, and frequency resolution was set to a $2.5 \mathrm{~Hz}$ interval. The impact hammer and vibration acceleration sensor were used in exponential windowing. In addition, the value was analyzed using a linear average of five times.

The response functions in the axial and radial directions on the side face of the wheel are shown in Fig. 4. Various natural frequencies can be observed in the axial and radial directions. Especially, periodic natural frequencies are observed at frequencies of $2000 \mathrm{~Hz}$ or greater. This shows that high noise in the wheel can be generated by the external stimulus at a high frequency range.

To examine the mode of the wheel more specifically, a numerical analysis was performed using a finite element model of the wheel [9]. Numerical analysis confirmed the dynamic characteristics of the wheel-set using ANSYS Mechanical. The wheel-set model was the same as the model used in the experiment, and the meshes were uniformly created using the sweep method so as to be optimal for a circular shape using 54,833 nodes and 11,970 elements. The material of the wheel was mild steel, the density was $7850 \mathrm{~kg} / \mathrm{m}^{3}$, the Young's modulus was set at $210 \mathrm{GPa}$, and the Poisson's ratio was 0.3 . The analysis was conducted from $2.5 \mathrm{~Hz}$ to $10 \mathrm{kHz}$ at $2.5 \mathrm{~Hz}$ intervals. The boundary conditions were set as free from all directions, and the axial direction was divided into axial and radial directions by a force of $1 \mathrm{~N}$.

The frequency response function and mode shape of the wheel with respect to each natural frequency are shown in Fig. 5. Although there was a slight difference between the analysis and test results in the radial direction, they show good

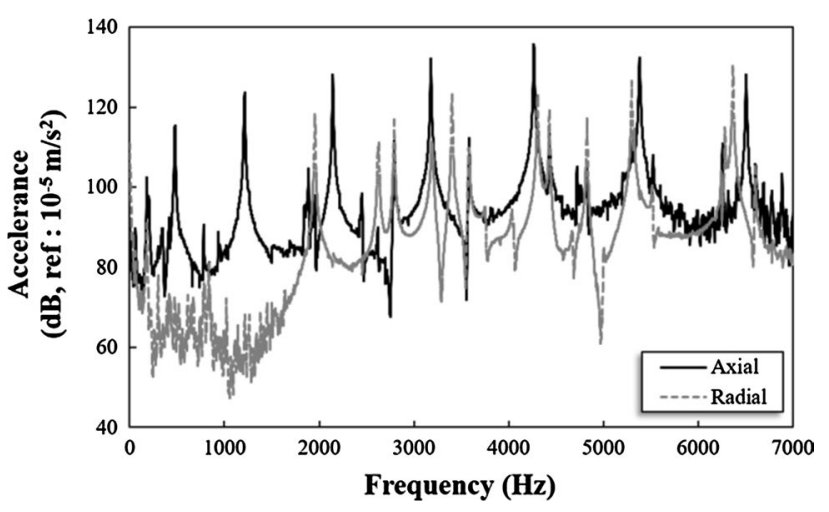

Fig. 4 Measurement results of modal test for wheel 
Fig. 5 Modes and natural frequency of wheel
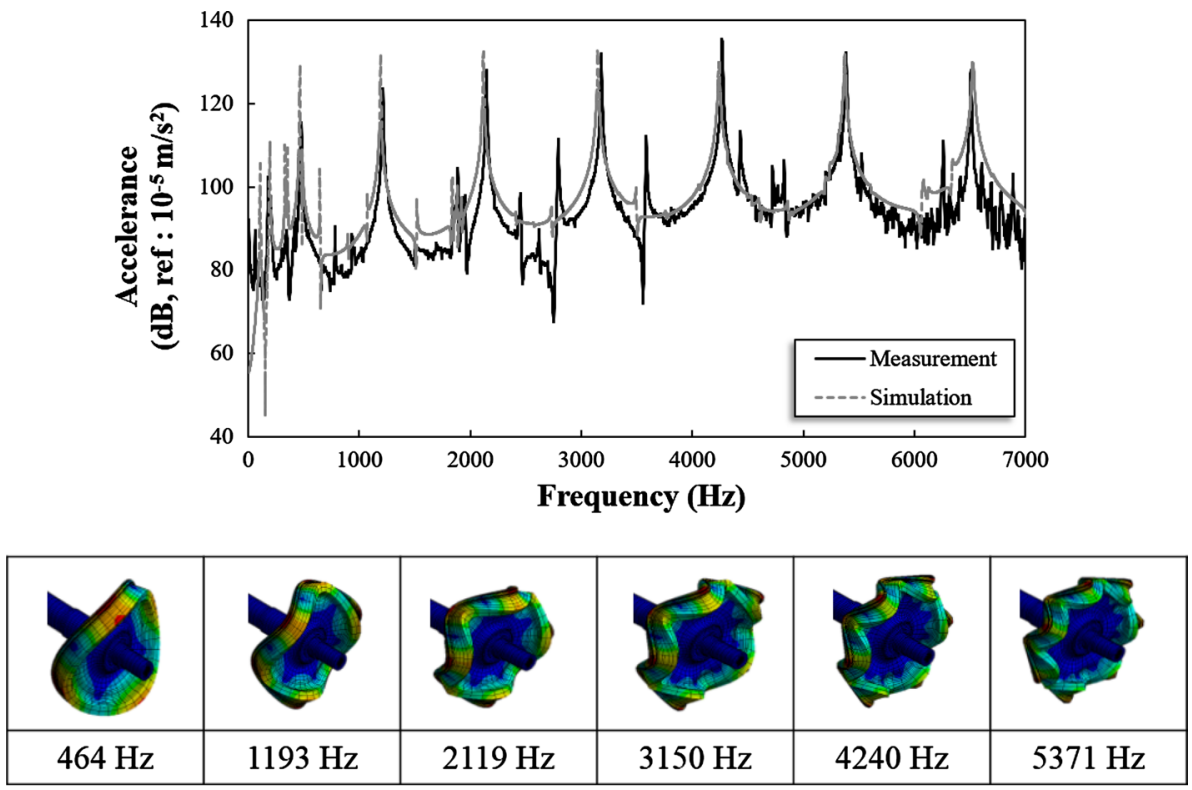

(a) Axial direction

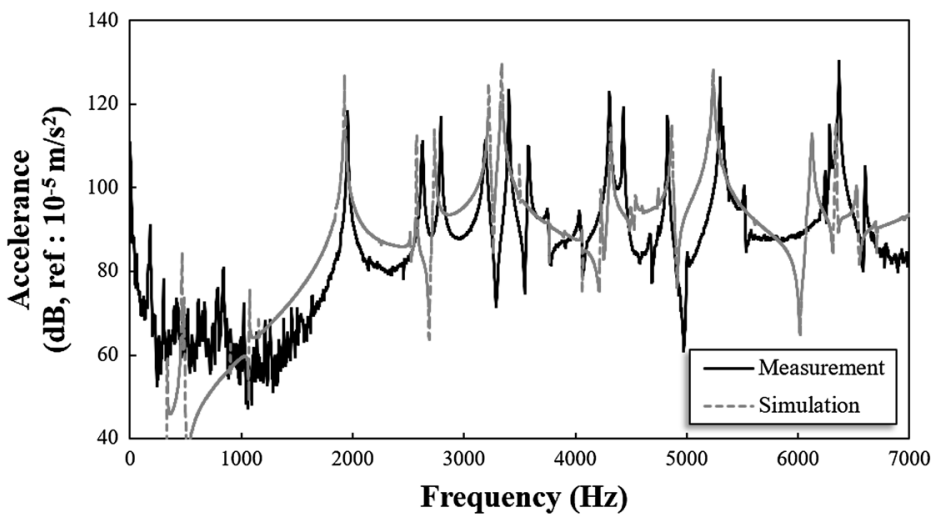

\begin{tabular}{|l|l|l|l|l|}
\hline & & & \\
\hline
\end{tabular}

(b) Radial direction

agreement in the axial direction. The difference in overall frequency was under $3 \%$, as shown in Table 1 . At a frequency of $4000 \mathrm{~Hz}$ or more, the radial mode was close to the resonant frequency in the axial direction mode. This seems to be due to the concentration of multiple modes in the high frequency region.

\section{Noise Measurement Using Full-Scale Test Rig}

It is difficult to distinguish the characteristics of wheel squeal and flange noises, as the two noises occur simultaneously when passing through a curved section. In this study, curve noises were reproduced using a full-scale test rig, as shown in Fig. 6. In the large-scale derailment tester, when 
Table 1 Comparison between finite elements and measured data

\begin{tabular}{lccll}
\hline Mode & FEM $(\mathrm{Hz})$ & Measured $(\mathrm{Hz})$ & Difference $(\%)$ & Mode shape \\
\hline 1 & 464 & 460 & 0.86 & Axial mode \\
2 & 1193 & 1193 & 0.00 & Axial mode \\
2 & 1927 & 1930 & 0.16 & Radial mode \\
3 & 2119 & 2118 & 0.07 & Axial mode \\
4 & 2575 & 2628 & 2.01 & Radial mode \\
5 & 3150 & 3180 & 0.95 & Axial mode \\
6 & 3338 & 3403 & 1.93 & Radial mode \\
7 & 4230 & 4308 & 1.83 & Radial mode \\
8 & 4240 & 4268 & 0.65 & Axial mode \\
9 & 5238 & 5300 & 1.18 & Radial mode \\
10 & 5371 & 5383 & 0.21 & Axial mode \\
11 & 6340 & 6370 & 0.47 & Radial mode \\
12 & 6528 & 6525 & 0.05 & Axial mode \\
\hline
\end{tabular}

the railing is driven, the axle mounted thereon is also driven. The horizontal actuator attached to the axle frame allows the lateral displacement to be adjusted, and the two vertical actuators allow the right and left axles to be weighted. The yaw angle and axle position can be adjusted using three actuators attached to the rail motor that control the speed of the vehicle. As described above, the yaw angle, vertical load, and lateral displacement of the wheel-sets can be adjusted so that the rig can simulate running the vehicle through a curve. To measure the noise generated when the axle is driven, a microphone was installed $1 \mathrm{~m}$ from the left and right sides of the axle at a height of $0.5 \mathrm{~m}$.

The wheel squeal and flange noise of the test rig-under controlled rail speed, yaw axis, vertical load, and lateral displacement conditions-are summarized in Table 2. The flange noise varies depending on the contact between the wheel and rail. In this test, a "ching-ching" sound was generated. The wheel squeal was measured at $100 \mathrm{~dB}$ (A) at $5340 \mathrm{~Hz}$ - a slight difference from the natural frequency

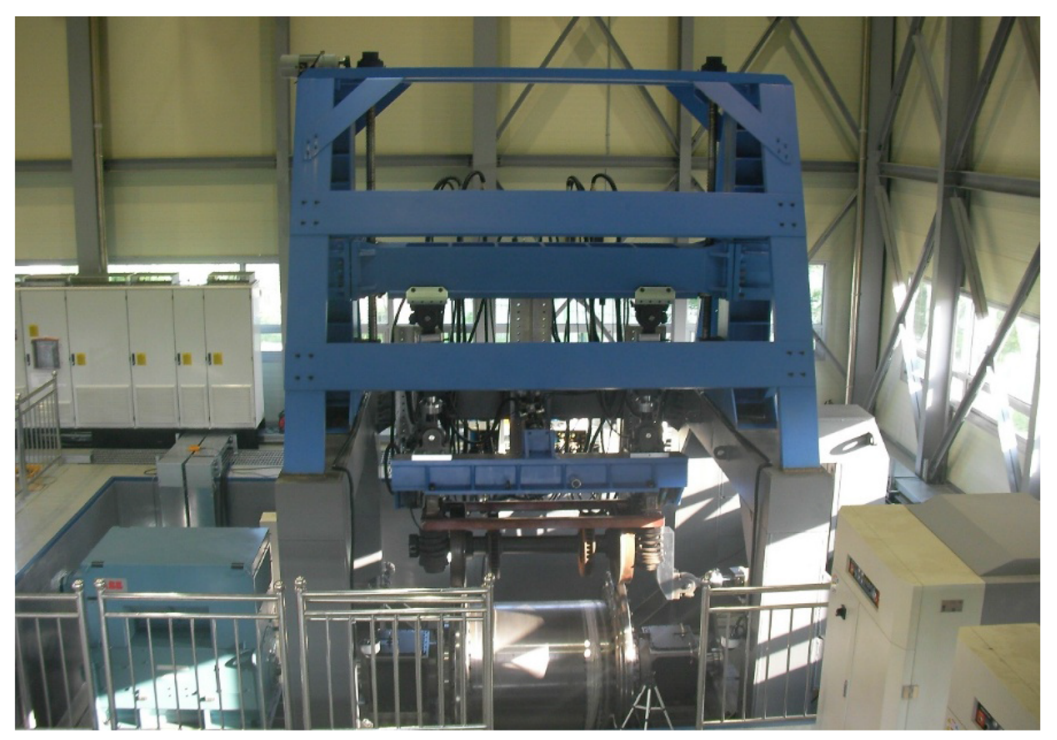

(a) Test facility
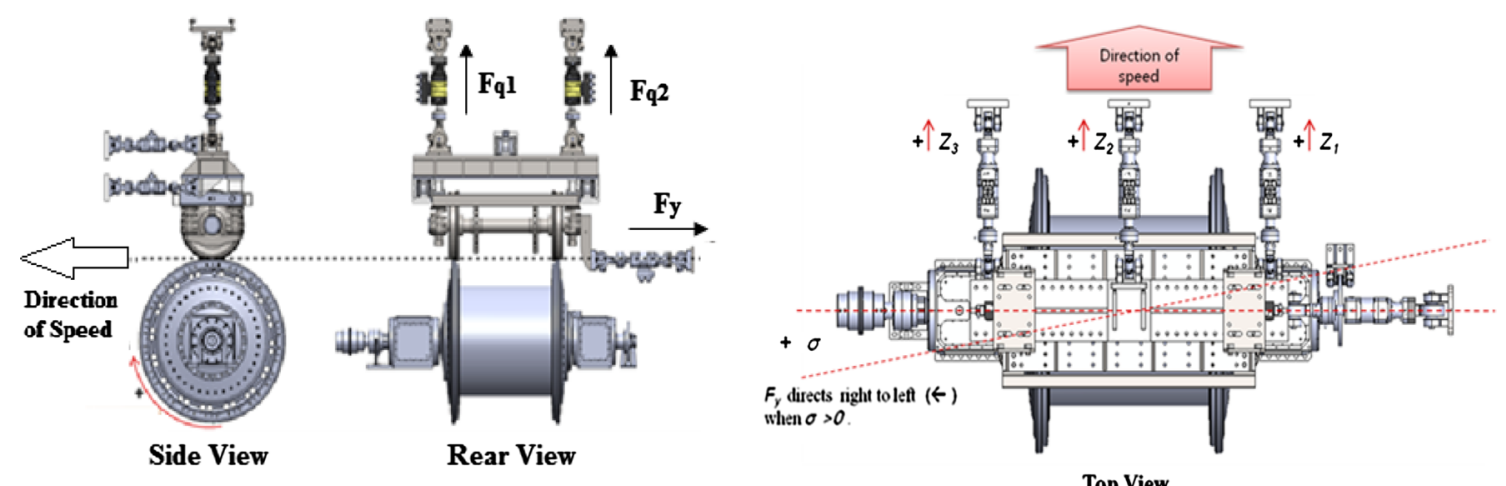

Top View

(b) Full-scale test rig

Fig. 6 Full-scale test rig 
Table 2 Test conditions of fullscale test rig

\begin{tabular}{lllllll}
\hline $\begin{array}{l}\text { No. } \\
\begin{array}{l}\text { Lateral } \\
\text { displacement } \\
(\mathrm{mm})\end{array}\end{array}$ & $\begin{array}{l}\text { Right verti- } \\
\text { cal load }(\mathrm{kN})\end{array}$ & $\begin{array}{l}\text { Left vertical } \\
\text { load }(\mathrm{kN})\end{array}$ & Yaw angle $\left(^{\circ}\right)$ & Speed $(\mathrm{km} / \mathrm{h})$ & Remarks \\
\hline 1 & -2.5 & 7 & -19 & 0.2 & 30 & Wheel squeal noise \\
2 & 3 & -28 & 15 & -0.5 & 20 & Flanging noise \\
\hline
\end{tabular}

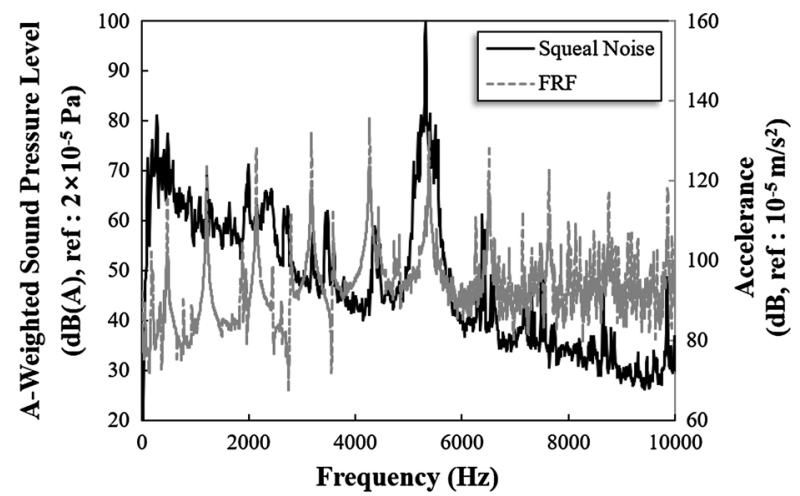

(a) Wheel squeal noise and accelerance of wheel side in axle direction

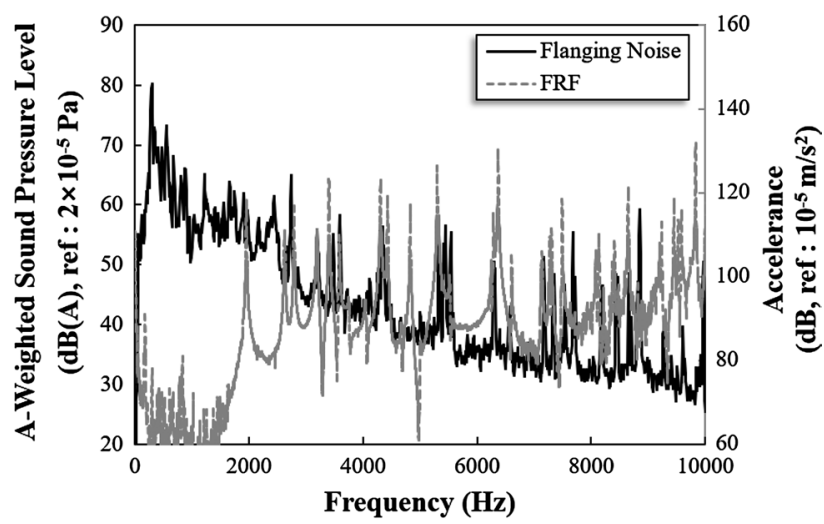

(b) Flanging noise and accelerance of wheel flange in radial direction

Fig. 7 Comparison of curve squeal noise and accelerance of wheel

$(5380 \mathrm{~Hz}$ ) obtained in the axial direction of the wheel-as shown in Fig. 7. The flange noise was much quieter than that of the wheel squeal and was the frequency was similar to the radial natural frequency of the wheel flange (within a range of approximately $5000-9000 \mathrm{~Hz}$ ). We thus concluded that wheel noise is closely related to the natural frequency in the axial direction of the wheel and that flange noise is closely related to the natural frequency in the radial direction of the wheel flange. Generally speaking, it is difficult to reproduce curve noise by using a large-scale test machine because the wheel condition may vary depending on the wear of the contact surfaces of the wheel and rail; the flange noise is more difficult to reproduce than wheel squeal.

\section{Noise Measurement of Field Test}

To analyze the characteristics of wheel squeal and flange noises, noise and vibration were measured at the curve of electric multiple unit (EMU) driving. The radius of the curve was $150 \mathrm{~m}$, and its cant was $50 \mathrm{~mm}$, as shown in Fig. 8. The gradient of the ground was $2 \%$. As shown in Fig. 9, there was severe wear on the side of the outer rail. For our measurements, four microphones were installed $0.5 \mathrm{~m}$ from the inner and outer rails, and four accelerometers were attached to the inner and outer rails to simultaneously measure noise and vibration. SIEMENS SCADAS Mobile was used for the measurement. Sampling frequency was set to $20,480 \mathrm{~Hz}$, and frequency resolution was set to a $2.5 \mathrm{~Hz}$ interval. The Hann function was used for the fast Fourier transform. The vehicle was run at $5 \mathrm{~km} / \mathrm{h}, 20 \mathrm{~km} / \mathrm{h}, 25 \mathrm{~km} / \mathrm{h}$, and $30 \mathrm{~km} / \mathrm{h}$.

To analyze the characteristics of curve noise, we analyzed noise and vibration for different vehicle speeds and directions of travel in a sharp curved section. Figure 10 shows the average noise level measured $0.5 \mathrm{~m}$ away from the low and high rails for different vehicle speeds. Figure 11 compares the sound pressure of the high and low rails at $20 \mathrm{~km} / \mathrm{h}$.

Curve squeal is constant regardless of vehicle speed, but the noise level is approximately $10 \mathrm{~dB}(\mathrm{~A})$ depending on the driving direction. When the vehicle travels from $A$ to $\mathrm{B}$, the noise level on the low rail is higher than that on the high rail by at least $5 \mathrm{~dB}(\mathrm{~A})$. However, when traveling in the opposite direction (from $B$ to $A$ ), the noise level of the high rail side is approximately $1-3 \mathrm{~dB}(\mathrm{~A})$ higher than that on the low rail. The noise generated in the outer rail may be caused by the flange due to contact between the wheel and the rail, and the radiation noise could be due to the vibration of the rail. On the downward slope, the contact force due to the flange increased, and the vibration of the outer rail also increased. In this case, the overall noise could increase [10]. However, there is a limit to understanding the exact mechanism of noise generation based on the measurements from this study. Additional research is needed to analyze more precise causes. 


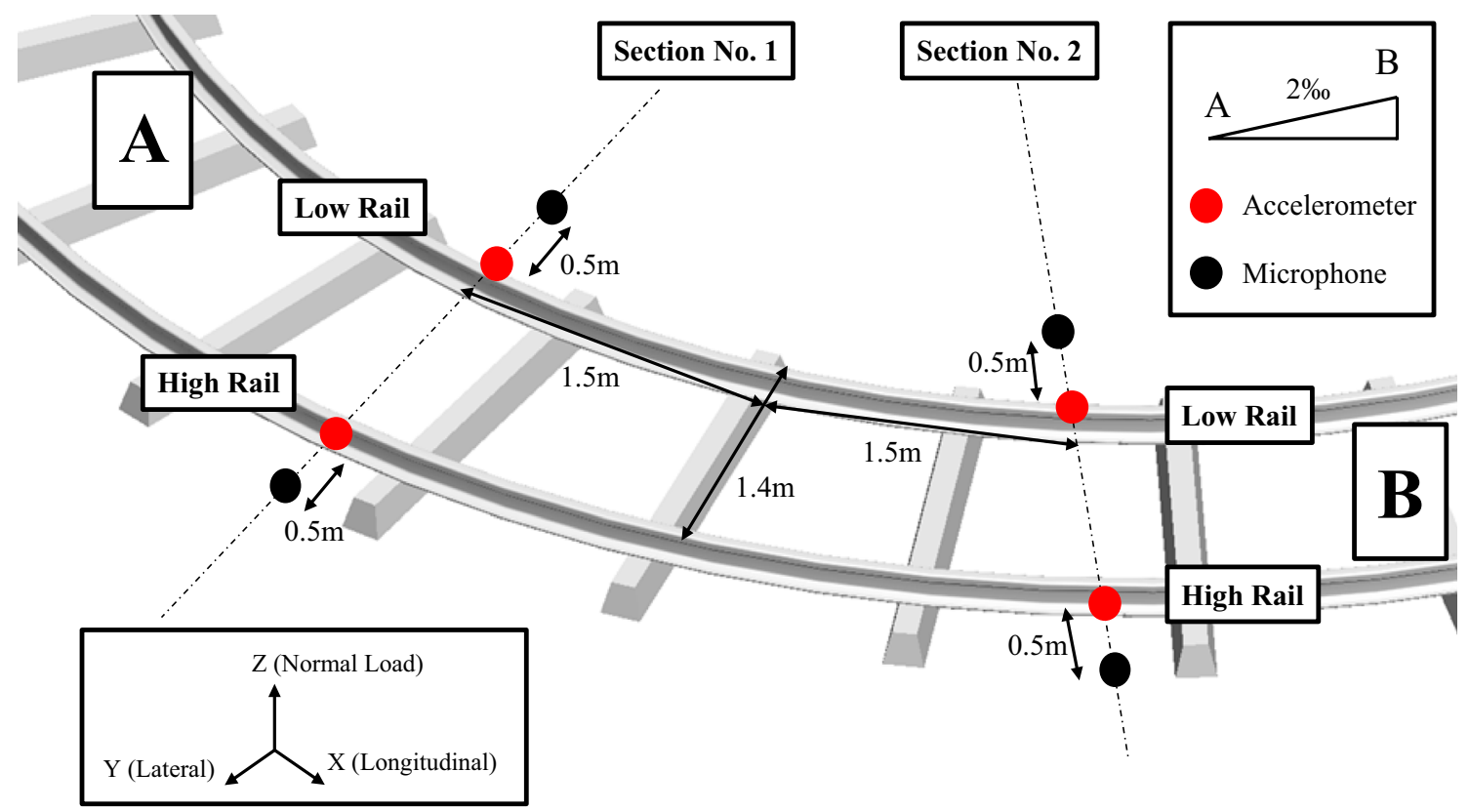

Fig. 8 Positions of microphone and accelerometer of field test

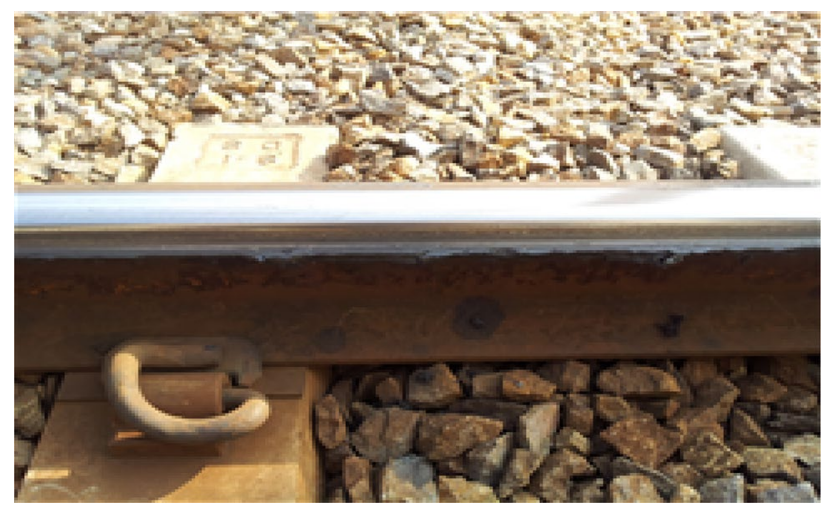

Fig. 9 Head check of high rail gauge in curve

To confirm that the characteristics of the squeal noise curve along the running direction and manifest differently, as shown in Fig. 12, we performed a noise level frequency analysis. Peaks are present at $470 \mathrm{~Hz}, 1200 \mathrm{~Hz}, 2100 \mathrm{~Hz}$, $4360 \mathrm{~Hz}$, and $5340 \mathrm{~Hz}$ from the inner rail when running from $\mathrm{A}$ to $\mathrm{B}$, and noise at frequencies higher than $7000 \mathrm{~Hz}$ is displayed on the outer rail. In addition, when traveling in the opposite direction, the noise level of the inner rail decreases by approximately $10 \mathrm{~dB}$ (A). Moreover, a high level of noise - in the 1000-10,000 Hz region-is observed on the outer rail. The resonance frequency in the axial direction of the wheel substantially coincides with the wheel squeal frequency as shown in Fig. 13. Therefore, it is possible to confirm that the noise caused by the bending modes of the

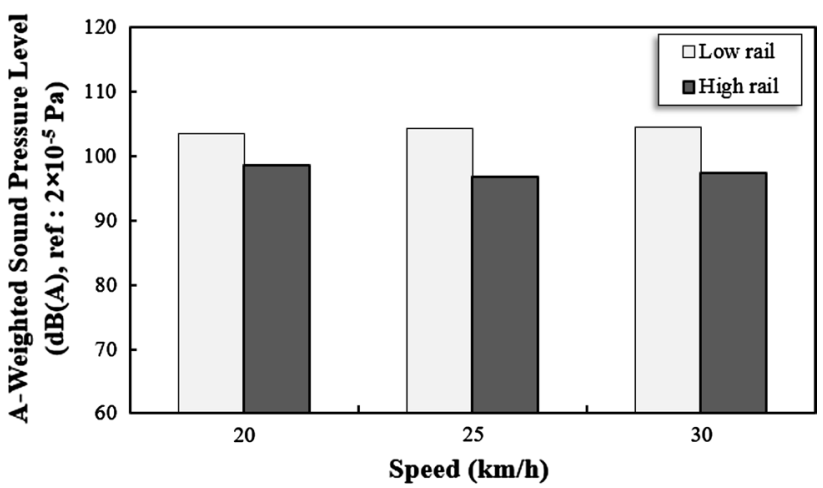

(a) Sound pressure level at direction from $\mathrm{A}$ to $\mathrm{B}$

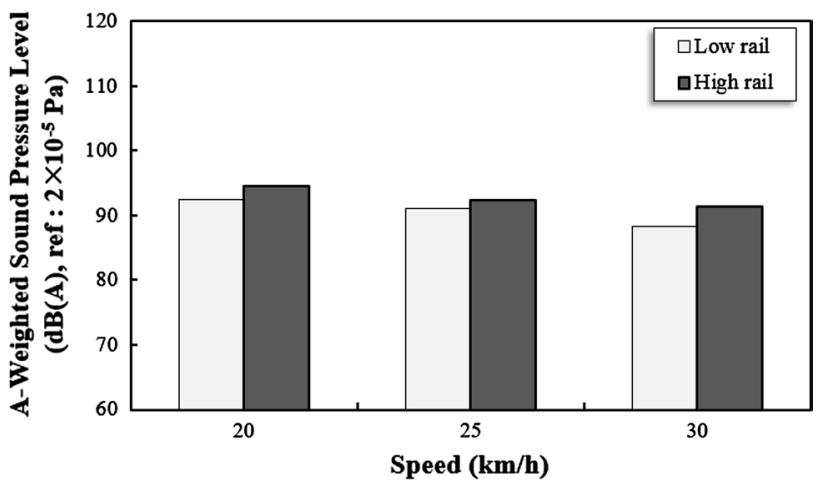

(b) Sound pressure level at direction from B to A

Fig. 10 Measurement results of sound pressure level at $0.5 \mathrm{~m}$ 


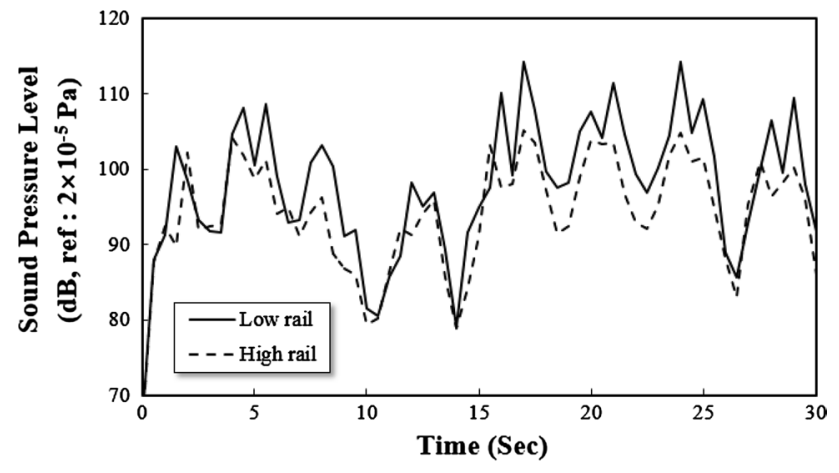

(a) Sound pressure level at direction from A to B

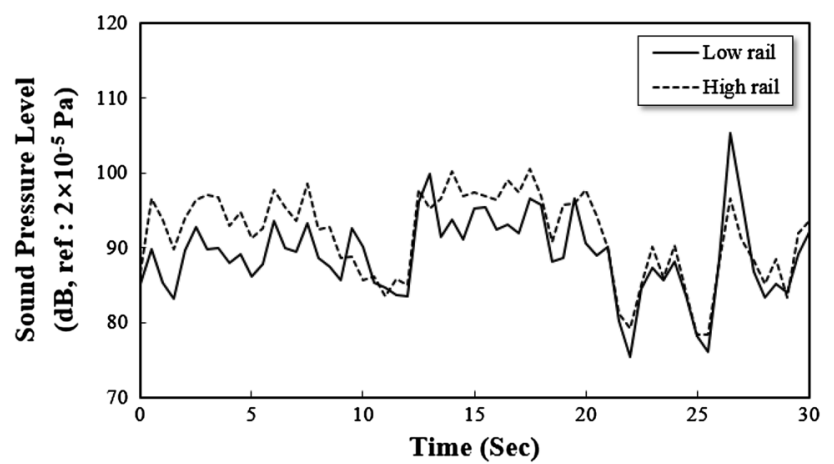

(b) Sound pressure level at direction from B to A

Fig. 11 Comparison of noise on low and high rail at $20 \mathrm{~km} / \mathrm{h}$

wheels generated from the inner rail is wheel squeal and that the noise generated from the outer rail is flange noise.

A frequency analysis of the noise measured at a point $0.5 \mathrm{~m}$ away from the inner rail when running at $30 \mathrm{~km} / \mathrm{h}$ is shown in Fig. 14. Although there are some peaks at frequencies of $470 \mathrm{~Hz}$ and $5340 \mathrm{~Hz}$, the wheel squeal noise is remarkably reduced. The decrease in the curve squeal noise occurring in the A-to-B direction in the field test is influenced by the gradient as shown in Fig. 15.

Furthermore, it was confirmed that the generation of noise in the curved portion increased with the increase in speed as shown in Fig. 16. Especially, it can be seen that the increase in the noise level occurred even at a speed of $10 \mathrm{~km} / \mathrm{h}$. Furthermore, if an analysis including the time domain, is performed, it can be confirmed that the occurrence frequency also increases at a speed of $10 \mathrm{~km} / \mathrm{h}$, as shown in Fig. 17.

The vibration level of the outer rail is larger than that of the inner rail, and the vibration level of the inner rail is similar in the vertical and horizontal directions; however, in the outer rail, the vibration level in the left and right directions is larger than that in the vertical direction, as shown in Fig. 18. This is

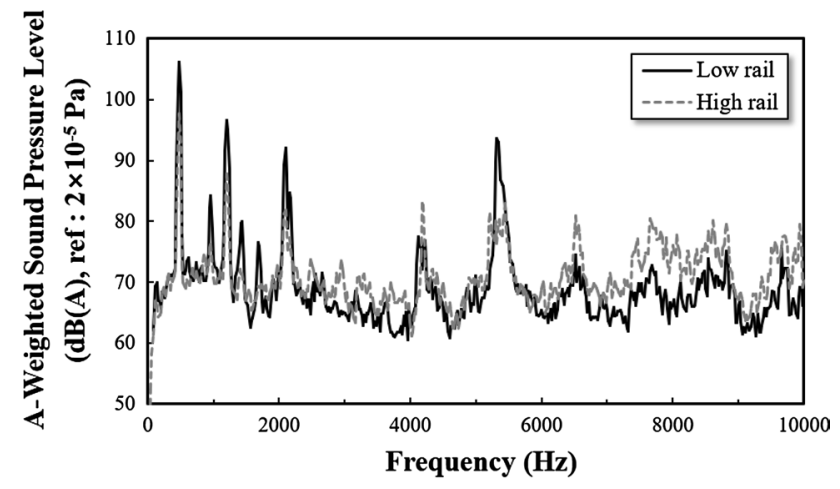

(a) Sound pressure level at direction from A to B

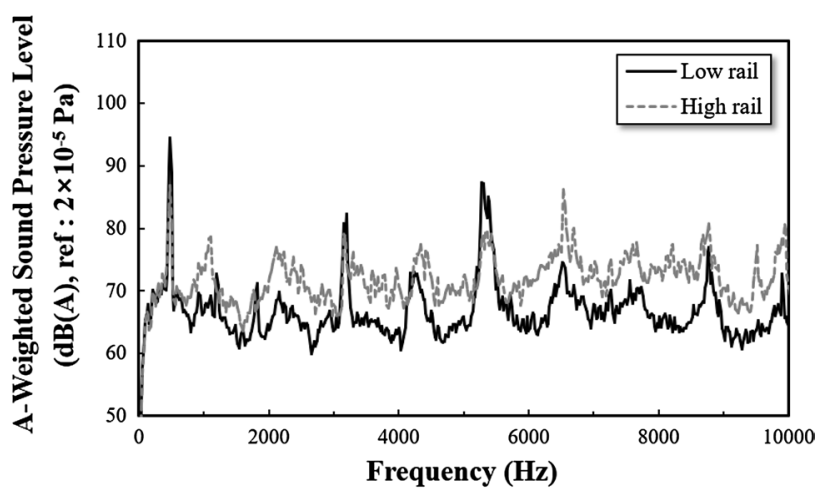

(b) Sound pressure level at direction from B to A

Fig. 12 Frequency analysis of noise on low and high rail at $20 \mathrm{~km} / \mathrm{h}$

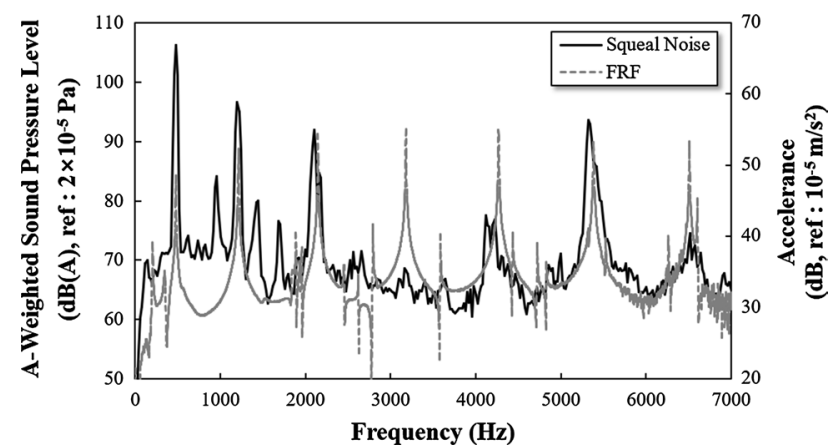

Fig. 13 Comparison of noise and frequency response functions (FRF) of wheel in axial direction at $20 \mathrm{~km} / \mathrm{h}$

a result of indirectly showing that the generation of the squeal noise and the vertical rail vibration are related to each other. In this section, the characteristics of noise generated in the actual curved section are analyzed based on various factors such as driving direction and speed. 


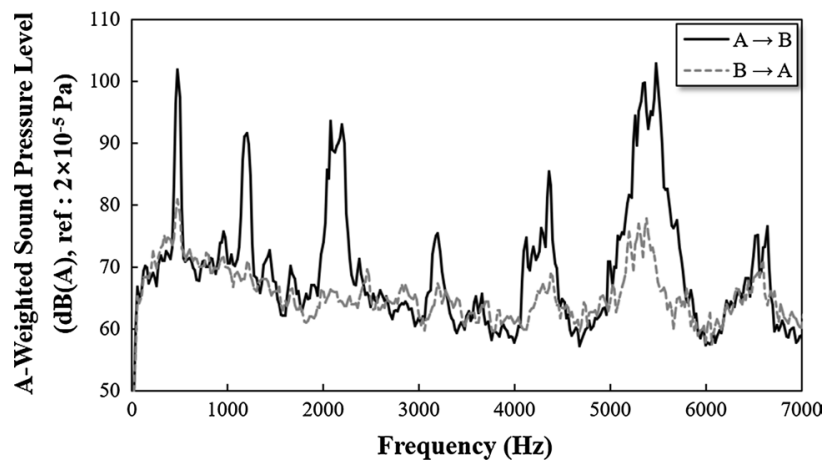

Fig. 14 Frequency analysis of sound pressure level on low level at $30 \mathrm{~km} / \mathrm{h}$

\section{Conclusions}

This study analyzed the causes of noise in a curved section through various experimental approaches. First, we investigated the noise characteristics of the railway vehicle through a structural analysis of the wheel. The results confirmed that the wheel has various natural frequencies and eigenmodes in a high frequency range. To investigate the characteristics of the noise generated when the wheel and rail are in contact with each other, a roller rig test was performed to measure the noise generated when the curved section runs through the actual wheel. Particularly, in this experiment, the squeal and flange noises were reproduced respectively by adjusting the lateral angle and vertical force. The results confirmed that squeal noise occurs in the high frequency region and the flange noise occurs in many modes. Furthermore, a study was conducted to measure and analyze noise in an actual urban railway curve section. Through a comparison of the frequency and natural

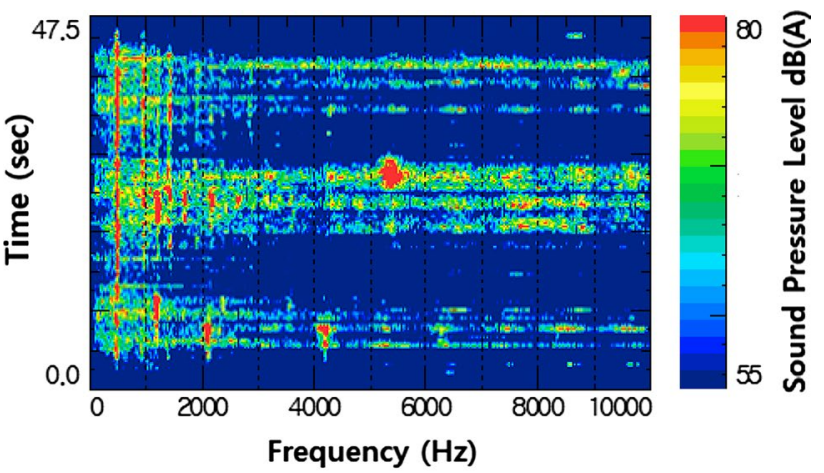

(a) $20 \mathrm{~km} / \mathrm{h}$

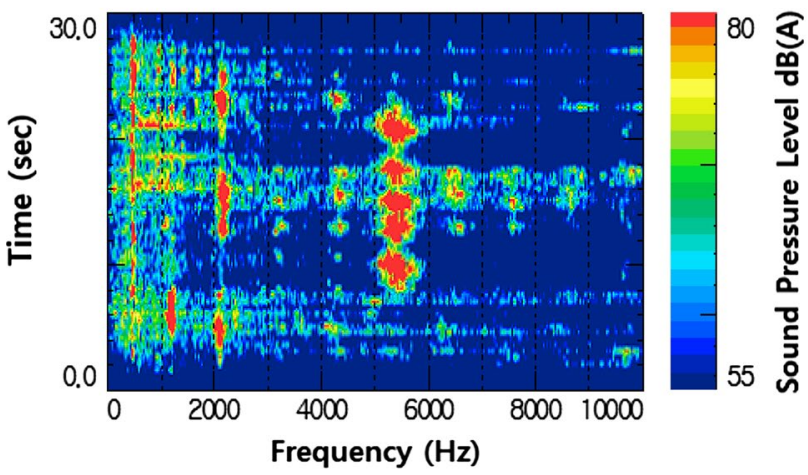

(b) $30 \mathrm{~km} / \mathrm{h}$

Fig. 16 Comparison of sound pressure levels at $20 \mathrm{~km} / \mathrm{h}$ and $30 \mathrm{~km} / \mathrm{h}$ in the time and frequency domain

frequency analyses of the actually measured noise, the wheel mode causing squeal noise was confirmed. In addition, the influence of the noise generated inside and outside the curved part was investigated by velocity and the influence on the curved part noise was examined. This
Fig. 15 Measurement results of rail vibration

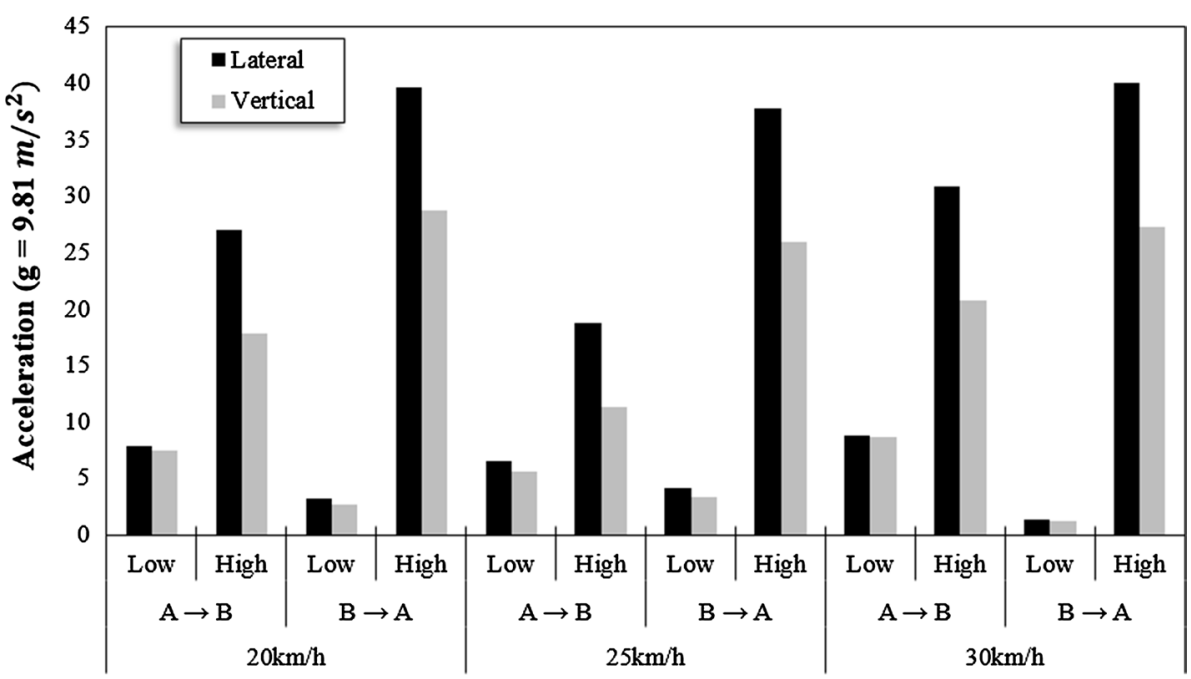




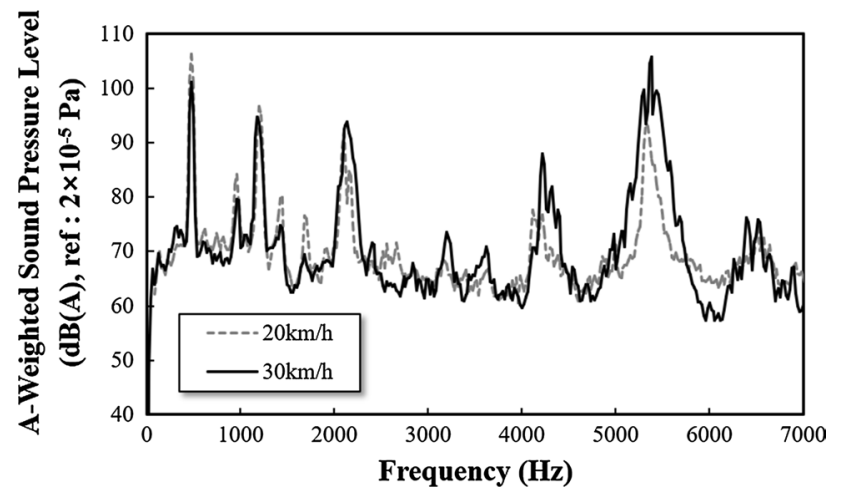

Fig. 17 Comparison of sound pressure levels at $20 \mathrm{~km} / \mathrm{h}$ and $30 \mathrm{~km} / \mathrm{h}$ in the frequency domain

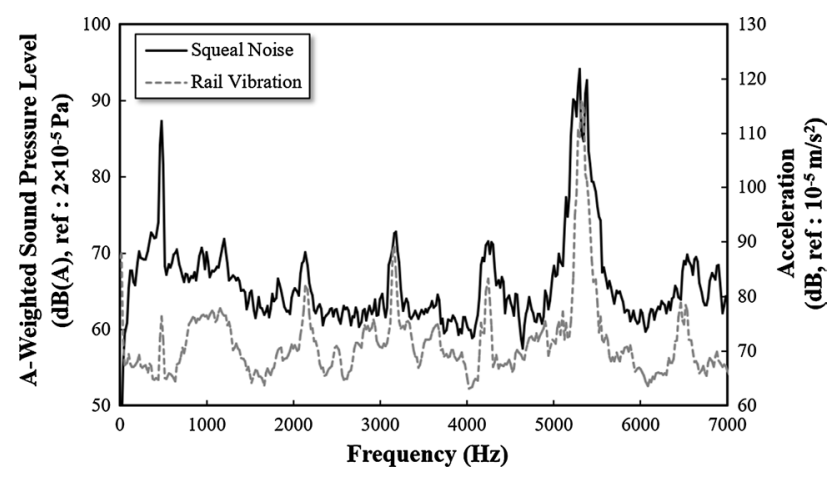

Fig. 18 Comparison of sound pressure level and rail vibration in vertical direction at $25 \mathrm{~km} / \mathrm{h}$

study provides information on the squeal and flange noises generated by a railway vehicle when passing through a curved section through various experimental approaches.

Acknowledgements This research was supported by a Grant (18TLRPC146729-01) from Railroad Technology Research Program funded by Ministry of Land, Infrastructure and Transport of Korean government and a grant from R\&D Program of the Korea Railroad Research Institute, Republic of Korea.

Open Access This article is distributed under the terms of the Creative Commons Attribution 4.0 International License (http://creativeco mmons.org/licenses/by/4.0/), which permits unrestricted use, distribution, and reproduction in any medium, provided you give appropriate credit to the original author(s) and the source, provide a link to the Creative Commons license, and indicate if changes were made.

\section{References}

1. Vincent, N., Koch, J. R., Chollet, H., \& Guerder, J. Y. (2006). Curve squeal of urban rolling stock-Part 1: State of the art and field measurements. Journal of Sound and Vibration, 293, 691-700.

2. Remington, P. J. (1986). Wheel/rail squeal and impact noise: What do se know? What don't we know? Where do we go from here? Journal of Sound and Vibration, 116(2), 339-353.

3. Rudd, M. J. (1976). Wheel/rail nose-part II: Wheel squeal. Journal of Sound and Vibration, 46, 381-394.

4. Eadie, Donald T., Santoro, Marco, \& Kalousek, Joe. (2005). Railway noise and the effect of top of rail liquid friction modifiers: Changes in sound and vibration spectral distributions in curves. Wear, 258, 1148-1155.

5. Anderson, D., \& Wheatley, N. (2008). Mitigation of wheel squeal and flanging noise on the Australian rail network. In B. SchulteWerning, et al. (Eds.), Noise and vibration mitigation for rail transportation systems. Notes on numerical fluid mechanics and multidisciplinary design (vol. 99, pp. 399-405). Berlin, Heidelberg: Springer.

6. Hiensch, Martin, Larsson, Per-Olof, et al. (2005). Two-material rail development: Field test results regarding rolling contact fatigue and squeal noise behavior. Wear, 258, 964-972.

7. Cervello, S., Donzella, G., Pola, A., \& Scepi, M. (2001). Analysis and design of a low-noise railway wheel. Proceedings of the Institution of Mechanical Engineers, Part F: Journal of Rail and Rapid Transit, 215, 179-192.

8. Stock, R., Santoro, M., Makowsky, T., Elvidge, D., \& Xia, P. (2018). Friction management as a sustainable solution for controlling noise at the wheel-rail interface. In D. Anderson, et al. (Eds.), Noise and vibration mitigation for rail transportation system. Notes on numerical fluid mechanics and multidisciplinary design (vol. 139, pp. 723-734). Cham: Springer.

9. Kim, Cheol, Kwon, Yonghwan, \& Kim, Dongwon. (2018). Analysis of low-frequency squeal in automotive disc brake by optimizing groove and caliper shapes. International Journal of Precision Engineering and Manufacturing, 19(4), 505-512.

10. Park, S. H., Kim, J. S., \& Choi, J. J. (2009). Reference slip ratio generation and adaptive sliding mode control for railway rolling stocks. International Journal of Precision Engineering and Manufacturing, 10(2), 39-44.

Publisher's Note Springer Nature remains neutral with regard to jurisdictional claims in published maps and institutional affiliations. 


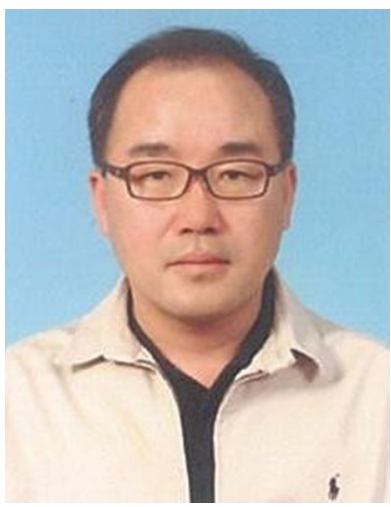

Jae Chul Kim is Principal Researcher at the Korea Railroad Research Institute. He rececived his M.S. and Ph.D. in the University of Toyko, Japan, in 1991-1996. His research interests include squeal noise, piezoelectric materials, and brake pad.

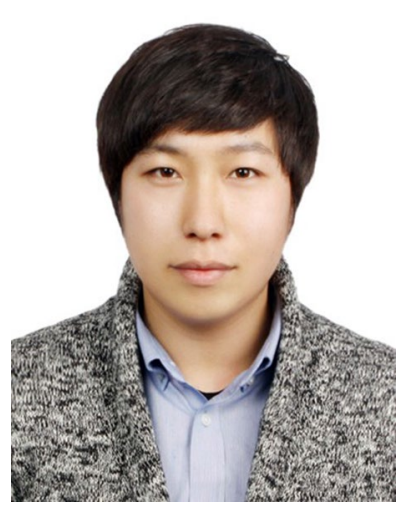

Yang Soo Yun is currently a $\mathrm{Ph}$. D. candidate in the Korea Railroad Research Institute School of University of Science and Technology. He is interested in NVH control of transportation. Specially, he studies about piezoelectric material and low friction material to reduction of noise and vibration.

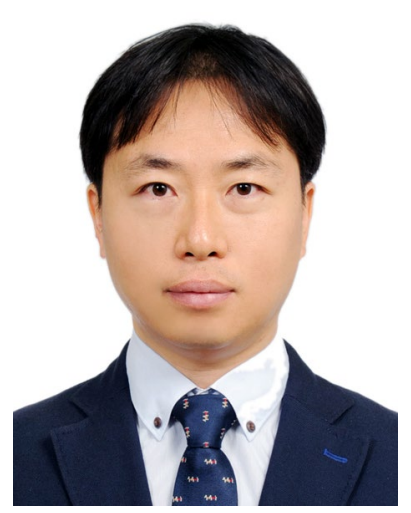

Hee-Min Noh is a senior researcher at Korea Railroad Research Institute. He received his Ph.D. in Industrial Engineering and Naval Architecture from Seoul National University. His research interest is sound visualization for noise source identification and noise reduction methods of high-speed train. 